\title{
Comparison of Antiviral Activity of Recombinant and Natural Interferons Against Crimean-Congo Hemorrhagic Fever Virus
}

\author{
Helen Karlberg ${ }^{1,2}$, Gunnel Lindegren ${ }^{1}$ and Ali Mirazimi ${ }^{* 1,2}$ \\ ${ }^{1} \mathrm{KCB} /$ Swedish Institute for Infectious Disease Control, SE-172 82 Solna, Sweden \\ ${ }^{2}$ Department of Microbiology, Tumor and Cell Biology, Karolinska Institutet, S-171 77 Stockholm, Sweden
}

\begin{abstract}
As a first line of defence against a virus infection, mammalian cells elicit an innate immune response, characterized by secretion of type I interferons (IFN) and up-regulation of interferon stimulated genes (ISGs). We have previously included Crimean Congo Hemorrhagic Fever Virus (CCHFV) in the list of type I IFN-sensitive viruses. In this in vitro study, we have compared the antiviral activity of two recombinant IFN-alpha preparations (Roferon A and Intron A) with a natural IFN-alpha produced in human leukocytes (Multiferon). Our results clearly demonstrate that these commercially available IFNs have significant antiviral activities against CCHFV. However, we could show that Multiferon inhibits viral replication more efficiently than the two recombinant IFN alpha preparations.
\end{abstract}

Keywords: Crimean Congo hemorrhagic fever virus, interferon, antiviral, CCHF, emerging disease.

\section{INTRODUCTION}

The innate immune response represents the first line of defence against a viral infection in mammalian cells [1,2]. The immune system is triggered when molecules produced during viral replication are detected by receptors on the surface or inside the host cell. Upon sensing those molecules, signalling pathways are activated leading to induction and secretion of type I interferons (IFNs), both IFN-alpha and IFN-beta, and subsequent up-regulation of interferon stimulated genes (ISGs) [3]. Type I IFNs are important mediators of innate immune responses and are crucial for limiting early replication and spread of viruses [3]. They induce a number of proteins involved in antiviral actions, such as 2',5'-oligoadenylate synthetase [4, 5], double-stranded RNA-activated protein kinase (PKR) [6], or Mx proteins [7-9]. In turn, the ISGs mediate antiviral, antiproliferative and immunomodulatory effects to protect surrounding cells from viral infections.

The importance of the IFN system is illustrated by the fact that numerous viruses encode gene products with antagonistic properties against the IFN-induced antiviral response [10].

The Bunyaviridae family is the largest virus family consisting of more than 300 enveloped viruses containing an RNA genome in negative-sense orientation [11]. The genome is divided into three segments designated $\mathrm{L}, \mathrm{M}$ and $\mathrm{S}$ encoding an RNA-dependent RNA polymerase, two glycoproteins ( $\mathrm{Gc}$ and $\mathrm{Gn}$ ) and a nucleocapsid protein (NP), respectively [12]. In addition, some members of the family encode non-structural proteins on their $\mathrm{M}$ or $\mathrm{S}$ segment termed NSm or NSs, respectively [13, 14]. Despite the increasing knowledge of the biology of the Bunyaviridae

*Address correspondence to this author at the Center for Microbiological Preparedness, Swedish Institute for Infectious Disease Control, 17282 Solna, Sweden; Tel: +46 (8) 4572573; Fax: +46 (8) 3079 57;

E-mail: Ali.Mirazimi@smi.ki.se family, little is known about Crimean Congo Hemorrhagic Fever Virus (CCHFV), a virus classified within the Nairovirus genus in this family and the causative agent of a severe hemorrhagic fever in humans [15]. The virus is transmitted either through bites by infected Ixodid ticks, or by direct contact with virus-contaminated blood. Even the nosocomial transmission has been reported.

The mortality rate varies depending on the mode of transmission; the reported mortality is $10-50 \%$ in cases of tick-to-human transmission, but even higher in the case of nosocomial infections [12, 16, 17]. Crimean Congo Hemorrhagic Fever (CCHF) progression is rapid. In severe cases, there is a short incubation period of 1 to 3 days after a tick bite before, severe hemorrhagic manifestations develop on the third to fifth day of disease, with death occurring during the second week of illness [15].

We have previously shown that type I IFNs have an antiviral effect against CCHFV [18], most likely due to the activities of IFN-induced antiviral proteins such as MxA [7], PKR or ISG20 (manuscripts in preparation). In this study, we have compared the in vitro antiviral activity of different recombinant IFNs and naturally produced IFN from human leukocytes.

Roferon A [19, 20] and Intron A [21] are recombinant forms of IFN subtypes alpha-2a and $-2 b$, respectively. These proteins have been manufactured by recombinant DNA technology. Multiferon $[22,23]$ is a natural IFN-alpha, which is obtained from the leukocyte fraction of human blood following induction with Sendai virus and subsequently purified by affinity chromatography. Multiferon contains various physiologically active IFN-alpha subtypes.

COMMERCIALLY AVAILABLE MULTIFERON HAS A BETTER ANTIVIRAL ACTIVITY COMPARED TO INTRON A AND ROFERON A

In order to compare the antiviral activity of the commercially available IFNs, A549 cells were treated with 
different concentrations (10, 100 and $1000 \mathrm{IU} / \mathrm{ml})$ of Multiferon, Roferon A or Intron A. Twenty four hours after treatment cells were infected with CCHFV strain IbAr 10200 , originally isolated in Nigeria in 1970, at various multiplicities of infection (MOI) ranging from 0.1 to 1 [24, 25]. Supernatants and cell lysates from mock- or IFN-treated cells were collected for detection of viral RNA and/or viral proteins at 48 hours post infection (h.p.i.).

Viral RNA was purified using the QIAamp Viral RNA Mini Kit (Qiagen) according to the manufacturer's instructions. Real-time reverse transcription-PCRs were performed as previously described by Wölfel et al. [26]. Briefly, primers targeting a $181 \mathrm{bp}$-long region in the $\mathrm{S}$ segment combined with 3 probes were included in the assay.
Five microliters of extracted RNA were then used as a template in a $25 \mu 1$ reaction volume and the cycling reactions were performed in a Roche Light Cycler 2.0. Reactions with crossing points below 35 cycles were defined as positive and plotted against a standard curve. Genome contents were calculated and presented as genomes $/ \mathrm{ml}$.

As shown in Fig. (1a), we could clearly demonstrate that Roferon A, Intron A and Multiferon have significant antiviral activities against CCHFV. These data could show that treatment of cells with $100 \mathrm{IU} / \mathrm{ml}$ of either Roferon A or Intron A inhibits the replication of CCHFV by at least one log while treatment with Multiferon inhibits viral replication by even two logs. Thus, Multiferon has a 10-times higher antiviral activity against CCHFV as compared to the

(a)

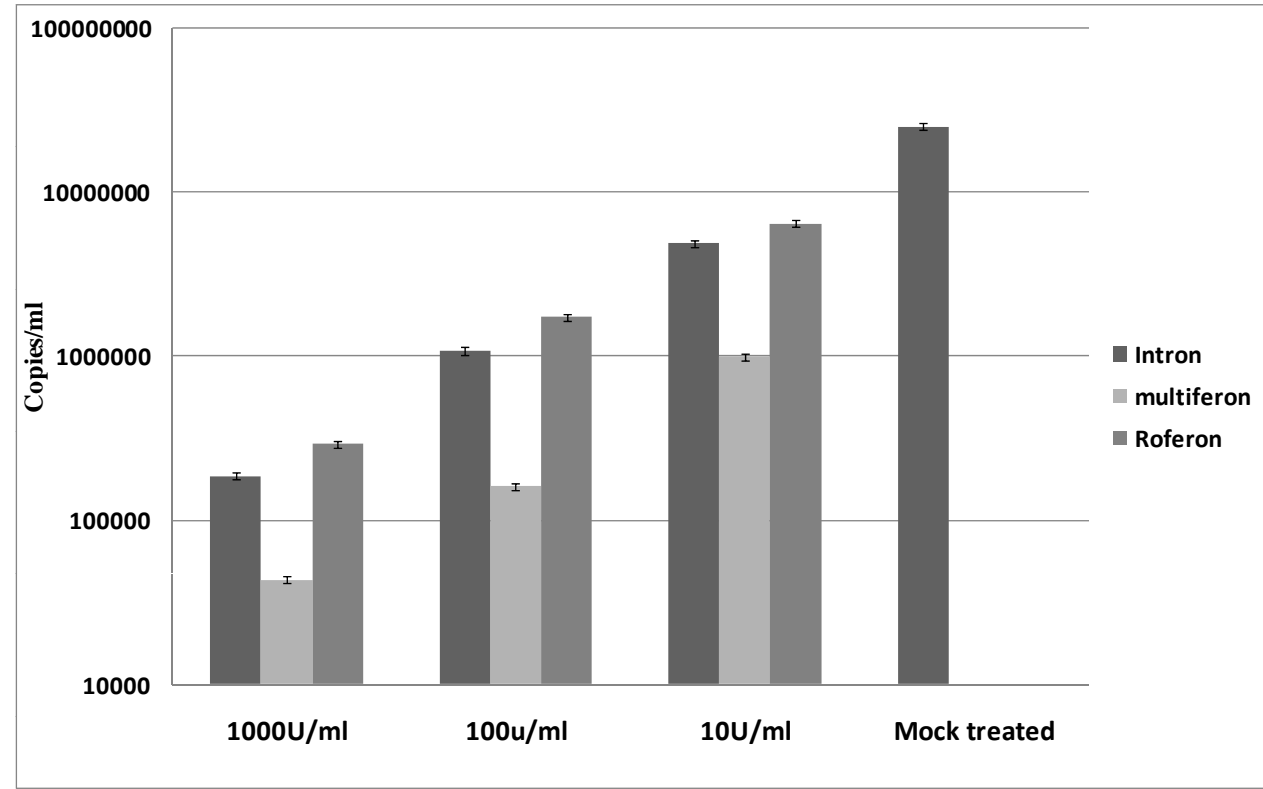

(b)

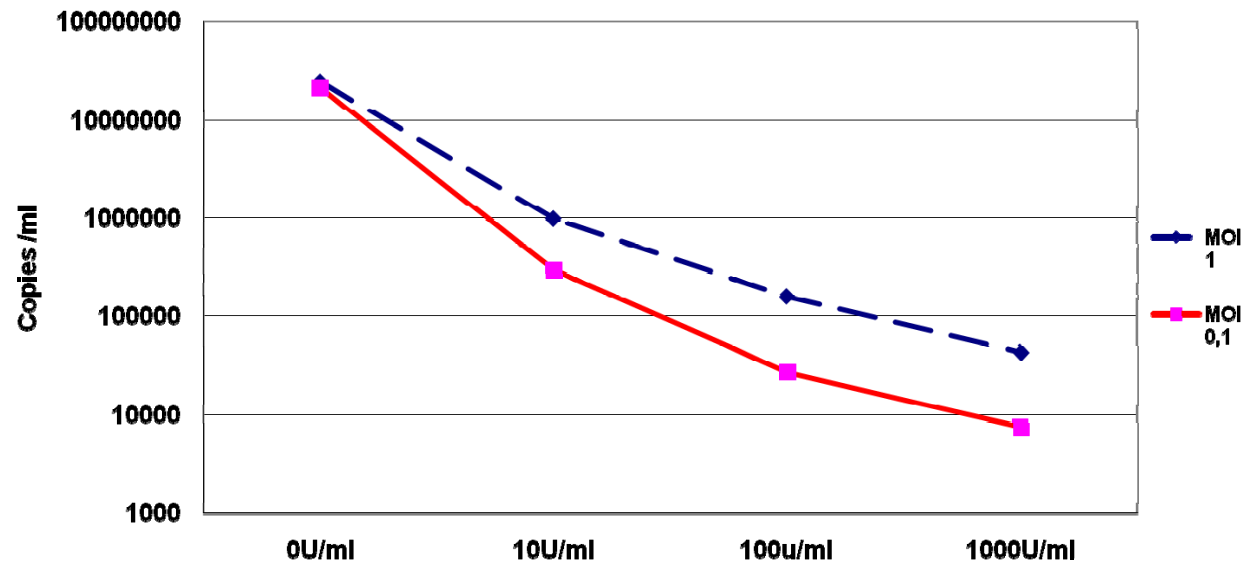

Fig. (1). a) Multiferon inhibits more efficiently the replication cycle of CCHFV compared to the others commercially available interferons. A549 cells were treated with different concentrations of IFNs for 24h. Mock-treated and IFN-treated cells were then infected with CCHFV (MOI 1). After another $48 \mathrm{~h}$ cell supernatants were collected and analyzed by real-time RT-PCR. Error bars demonstrate \pm SD based on three separate experiments. b) Comparison of inhibition of CCHFV genome contents in cell supernatants after pre-treated with different concentrations of Multiferon. A549 cells were treated with different concentrations of Multiferon for 24h. The mock-treated and Multiferontreated cells were then infected with CCHFV (MOI 0,1 and 1). After another 48h cell supernatants were collected and analyzed by real-time RT-PCR. 
recombinant IFNs. As expected, the antiviral activity of Multiferon was even more pronounced when the pre-treated cells were infected with less virus (Fig. 1b).

To confirm these results, we analyzed the expression of CCHFV NP in mock-treated and IFN-treated cells by Western blot (WB) (Fig. 2).

\begin{tabular}{|c|c|c|c|c|c|c|}
\hline \multicolumn{2}{|c|}{$R$} & \multicolumn{2}{|c|}{ I } & \multicolumn{2}{|c|}{$M$} & \\
\hline$\frac{\bar{\xi}}{\grave{D}}$ & $\begin{array}{l}\bar{\Xi} \\
\bar{\partial} \\
\stackrel{0}{0}\end{array}$ & $\begin{array}{l}\bar{\xi} \\
\bar{\partial}\end{array}$ & $\begin{array}{l}\bar{g} \\
\text { J } \\
0\end{array}$ & $\frac{\bar{\xi}}{\bar{\delta}}$ & 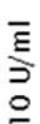 & $\overline{\mathrm{E}}$ \\
\hline
\end{tabular}

Fig. (2). Cells were pre-treated with either Roferon A (R), Intron A (I) or Multiferon (M) at different concentrations for 24h. Cells were then infected with CCHFV (MOI 0,1-1) and 24h later cell lysates were harvested for Western Blot analysis.

Cell lysates were resuspended in reducing sample buffer, boiled for five minutes and separated on SDS-PAGE with a 5\%-concentration gel and 10\%-separation gel. Electrophoresis was carried out at a constant current of 25 A. Proteins were transferred to a nitrocellulose membrane at $100 \mathrm{~V}$ for 1h using a transfer buffer containing $25 \mathrm{mM}$ Tris, $192 \mathrm{mM}$ glycine and $20 \%(\mathrm{v} / \mathrm{v})$ methanol. Membranes were then blocked in $5 \%$ non-fat dry milk over night at $+4^{\circ} \mathrm{C}$. After washing in PBS containing $0.01 \%$ Tween (PBST), the membranes were incubated with a polyclonal rabbit-antiCCHFV NP-antibody in dilution buffer ( $5 \%$ non-fat dry milk in PBST) for $1 \mathrm{~h}$ at room temperature. The membranes were then washed three times with PBST before incubating them with goat-anti-rabbit IgG HRP-conjugated antibody in dilution buffer for $1 \mathrm{~h}$ at room temperature. After careful washing, detection was carried out using ECL Plus Western Blotting Detection Reagents (Amersham Pharmacia) according to the manufacturer's instructions.

As shown in Fig. (2), Roferon A, Intron A and Multiferon reduced the expression of NP significantly. Moreover, these results confirm that Multiferon has a higher antiviral activity against CCHFV as compared to the other IFNs.

In this study, we demonstrate that commercially available IFN-alpha preparations have a strong antiviral activity against CCHFV when the cells are pre-treated before infection. We could also show that the naturally produced IFN from human leukocytes, Multiferon, has a significantly higher antiviral activity in vitro compared to recombinant IFNs. This study did not address the specific reason for the observed superior efficiency of Multiferon. However, Multiferon contains several naturally occurring subtypes of IFN-alpha and could therefore activate the antiviral state of the treated cells more efficiently.

IFNs are key players in host responses in the very early steps of infection $[10,27]$. The use of IFNs as therapeutics began soon after their potent antiviral activity had been discovered [28, 29]. Today, recombinant IFN-alpha is established as a key component of Hepatitis C treatment strategies, widely used in patients with chronic disease [30]. In recent years, it has been demonstrated that the use of IFNalpha in combination with ribavirin [31] yielded much higher success rates of the treatment. Moreover, it has been shown that switching to purified IFN-alpha from human leukocytes during an antiviral treatment could achieve a sustained immune response in patients [22,23]. Clinical studies have demonstrated that IFN has antiviral activity also against rhinovirus [32]. A recent study by Kugel et al. suggests that IFN treatment by nasal route may protect high risk groups against seasonal influenza [33].

The only known and used antiviral drug against CCHFV is ribavirin, a synthetic guanosine analogue [12]. Ribavirin has been approved for clinical use during treatment of, amongst other, Hepatitis C virus or respiratory syncytial virus infections [34-36] and is used off-label for treatment of patients with CCHFV infections [37-40]. However, the mechanism of action of ribavirin against CCHFV is still poorly understood and a discussion is still ongoing whether or not patients infected with CCHFV actually benefit from being treated with this drug. Whether IFN-alpha can be beneficial for treatment of patients with CCHFV in very early phase of disease alone or combination with ribavirin is not addressed before. It should be mentioned that interferon most probably induce the inflammatory response in these patients, and thereby can have a negative effect in progress of the disease. However, to address if IFN-alpha can be used as treatment in very early step of infection or as prophylaxis for persons exposed to the virus, detailed studies in animal models are needed.

\section{ACKNOWLEDGEMENT}

This study has partly been supported by Swedish Orphan International.

\section{REFERENCES}

[1] Bonjardim CA, Ferreira PC, Kroon EG. Interferons: signaling, antiviral and viral evasion. Immunol Lett 2009; 122: 1-11.

[2] Garcia-Sastre A, Biron CA. Type 1 interferons and the virus-host relationship: a lesson in detente. Science 2006; 312: 879-82.

[3] Randall RE, Goodbourn S. Interferons and viruses: an interplay between induction, signalling, antiviral responses and virus countermeasures. J Gen Virol 2008; 89: 1-47.

[4] Silverman RH. Viral encounters with 2',5'-oligoadenylate synthetase and RNase L during the interferon antiviral response. J Virol 2007; 81: 12720-9.

[5] Silverman RH. A scientific journey through the 2-5A/RNase L system. Cytokine Growth Factor Rev 2007; 18: 381-8.

[6] Samuel MA, Whitby K, Keller BC, et al. PKR and RNase L contribute to protection against lethal West Nile Virus infection by controlling early viral spread in the periphery and replication in neurons. J Virol 2006; 80: 7009-19.

[7] Andersson I, Bladh L, Mousavi-Jazi M, et al. Human MxA protein inhibits the replication of Crimean-Congo hemorrhagic fever virus. J Virol 2004; 78: 4323-9.

[8] Brzozka K, Finke S, Conzelmann KK. Identification of the rabies virus alpha/beta interferon antagonist: phosphoprotein $\mathrm{P}$ interferes with phosphorylation of interferon regulatory factor 3. J Virol 2005; 79: 7673-81.

[9] Haller O, Frese M, Kochs G. Mx proteins: mediators of innate resistance to RNA viruses. Rev Sci Tech 1998; 17: 220-30.

[10] Haller O, Weber F. The interferon response circuit in antiviral host defense. Verh K Acad Geneeskd Belg 2009; 71: 73-86.

[11] Schmaljohn A, Hooper JW. Bunyaviridae: the viruses and their replication. In: Knipe DM, Howley PM, Eds. Fields Virology, Lippincott, Williams and Wilkins: Philadelpia 2001; pp. 1447-72. 
[12] Whitehouse, C.A. Crimean-Congo hemorrhagic fever. Antiviral Res 2004; 64: 145-60.

[13] Erickson BR, Deyde V, Sanchez AJ, Vincent MJ, Nichol ST. Nlinked glycosylation of Gn (but not Gc) is important for Crimean Congo hemorrhagic fever virus glycoprotein localization and transport. Virology 2007; 361: 348-55.

[14] Ikegami T, Won S, Peters CJ, Makino S. Rift Valley fever virus NSs mRNA is transcribed from an incoming anti-viral-sense $\mathrm{S}$ RNA segment. J Virol 2005; 79: 12106-11.

[15] Weber F, Mirazimi A. Interferon and cytokine responses to Crimean Congo hemorrhagic fever virus; an emerging and neglected viral zonoosis. Cytokine Growth Factor Rev 2008; 19: 395-404.

[16] Swanepoel R. Crimean-Congo haemorrhagic fever. Cape Town: Oxford University Press 1994; pp. 723-9.

[17] Swanepoel R, Shepherd AJ, Leman PA, et al. Epidemiologic and clinical features of Crimean-Congo hemorrhagic fever in southern Africa. Am J Trop Med Hyg 1987; 36: 120-32.

[18] Andersson I, Lundkvist A, Haller O, Mirazimi A. Type I interferon inhibits Crimean-Congo hemorrhagic fever virus in human target cells. J Med Virol 2006; 78: 216-22.

[19] Brook MG, McDonald JA, Karayiannis P, et al. Randomised controlled trial of interferon alfa $2 \mathrm{~A}$ (rbe) (Roferon-A) for the treatment of chronic hepatitis B virus (HBV) infection: factors that influence response. Gut 1989; 30: 1116-22.

[20] Lai CL, Lok AS, Lin HJ, Wu PC, Yeoh EK, Yeung CY. Placebocontrolled trial of recombinant alpha 2-interferon in Chinese HBsAg-carrier children. Lancet 1987; 2: 877-80.

[21] Choueiri TK, Hutson TE, Bukowski RM. Evolving role of pegylated interferons in metastatic renal cell carcinoma. Expert Rev Anticancer Ther 2003; 3: 823-9.

[22] Musch E, Malek M, von Eick H, Chrissafidou A. Successful application of highly purified natural interferon alpha (multiferon) in a chronic hepatitis $\mathrm{C}$ patient resistant to preceding treatment approaches. Hepatogastroenterology 2004; 51: 1476-9.

[23] Musch E, Malek M, von Eick H, Chrissafidou A. Successful longterm application of highly purified natural interferon-alpha (multiferon) after preceding interferon approaches in a chronic hepatitis C patient with thrombocytopenia. Scand J Infect Dis 2004; 36: 395-9.

[24] Andersson I, Simon M, Lundkvist A, et al. Role of actin filaments in targeting of Crimean Congo hemorrhagic fever virus nucleocapsid protein to perinuclear regions of mammalian cells. J Med Virol 2004; 72: 83-93.

[25] Flick R, Flick K, Feldmann H, Elgh F. Reverse genetics for crimean-congo hemorrhagic fever virus. J Virol 2003; 77: 59976006.
[26] Wölfel R, Paweska JT, Petersen N, et al. Virus detection and monitoring of viral load in Crimean-Congo hemorrhagic fever virus patients. Emerg Infect Dis 2007; 13: 1097-100.

[27] Weber F, Haller O. Viral suppression of the interferon system. Biochimie 2007; 89: 836-42.

[28] Borecky L. Current view on the perspectives of interferon therapy. Acta Virol 1986; 30: 161-9.

[29] Borecky L, Fuchsberger N. Interferon as therapeutic agent. Acta Virol 1983; 27: 359-70.

[30] Hoofnagle JH, Seeff B. Peginterferon and ribavirin for chronic hepatitis C. N Engl J Med 2006; 355: 2444-51.

[31] McHutchison J, Blatt L, Sedghi-Vaziri A, Russell J, Schmid P, Conrad A. Is there an optimal time to measure quantitative HCV RNA to predict non-response following interferon treatment for chronic HCV infection? J Hepatol 1998; 29: 362-8.

[32] Finter NB, Chapman S, Dowd P, et al. The use of interferon-alpha in virus infections. Drugs 1991; 42: 749-65.

[33] Kugel D, Kochs G, Obojes K, et al. Intranasal administration of alpha interferon reduces seasonal influenza A virus morbidity in ferrets. J Virol 2009; 83: 3843-51.

[34] Wawrzynowicz-Syczewska M. Ribavirin--pharmacological features, antiviral effects against hepatitis $\mathrm{C}$ virus (HCV) and other viruses and side effects during treatment. Przegl Epidemiol 2002; 56(Suppl 5): 35-40.

[35] Schleuning M, Buxbaum-Conradi H, Jäger G, Kolb HJ Intravenous ribavirin for eradication of respiratory syncytial virus (RSV) and adenovirus isolates from the respiratory and/or gastrointestinal tract in recipients of allogeneic hematopoietic stem cell transplants. Hematol J 2004; 5: 135-44.

[36] Cooper KE. The effectiveness of ribavirin in the treatment of RSV. Pediatr Nurs 2001; 27: 95-8.

[37] Ergonul O, DEBATE (see Elaldi N, et al. Efficacy of oral ribavirin treatment in Crimean-Congo haemorrhagic fever: a quasiexperimental study from Turkey. Journal of Infection 2009; 58 238-244): biases and misinterpretation in the assessment of the efficacy of oral ribavirin in the treatment of Crimean-Congo hemorrhagic fever. J Infect 2009; 59: 284-6.

[38] Dizbay M, Aktas F, Gaygisiz U, Ozger HS, Ozdemir K. CrimeanCongo hemorrhagic fever treated with ribavirin in a pregnant woman. J Infect 2009; 59: 281-3.

[39] Tasdelen Fisgin N, Ergonul O, Doganci L, Tulek N. The role of ribavirin in the therapy of Crimean-Congo hemorrhagic fever: early use is promising. Eur J Clin Microbiol Infect Dis 2009; 28: 929-33.

[40] Izadi S, Salehi M. Evaluation of the efficacy of ribavirin therapy on survival of Crimean-Congo hemorrhagic fever patients: a casecontrol study. Jpn J Infect Dis 2009; 62: 11-5. 